\title{
DETECTION OF UNAUTHORIZED CONSTRUCTION EQUIPMENT IN PIPELINE RIGHT-OF-WAYS
}

QUARTERLY TECHNICAL REPORT

(October 1 through-December 31, 2002)

Principal Investigator: James E. Huebler

847-768-0551,jim.huebler@gastechnology.org

Report Issue Date: January 29, 2003

DOE Contract \#: DE-FC26-01NT41160

Submitted by

Gas Technology Institute 1700 South Mount Prospect Road

Des Plaines, Illinois 60018

GTI Project Number: 61139

Submitted to

NETL AAD Document Control Bldg. 921

U.S. Department of Energy

National Energy Technology Laboratory

P.O. Box 10940

Pittsburgh, PA 15236-0940

DOE Project Officer

Daniel J. Driscoll 


\section{DISCLAIMER}

"This report was prepared as an account of work sponsored by an agency of the United States Government and the Gas Technology Institute (GTI). Neither the United States Government, nor GTI, nor any agency thereof, nor any of their employees, makes any warranty, express or implied, or assumes any legal liability or responsibility for the accuracy, completeness, or usefulness of any information, apparatus, product, or process disclosed, or represents that its use would not infringe privately owned rights. Reference herein to any specific commercial product, process, or service by trade name, trademark, manufacturer, or otherwise does not necessarily constitute or imply its endorsement, recommendation, or favoring by the United States Government, GTI, or any agency thereof. The views and opinions of authors expressed herein do not necessarily state or reflect those of the United States Government or any agency thereof." 


\begin{abstract}
Natural gas transmission companies mark the right-of-way areas where pipelines are buried with warning signs to prevent accidental third-party damage. Nevertheless, pipelines are sometimes damaged by third-party construction equipment. A single incident can be devastating, causing death and millions of dollars of property loss. This damage would be prevented if potentially hazardous construction equipment could be detected, identified, and an alert given before the pipeline was damaged.

The Gas Technology Institute (GTI) is developing a system to solve this problem by using an optical fiber as a distributed sensor and interrogating the fiber with a custom optical time domain reflectometer. Key issues are the ability to detect encroachment and the ability to discriminate among potentially hazardous and benign encroachments.

The work performed in the $4^{\text {th }}$ quarter of 2002 included fine-tuning and debugging of the custom Optical Time Domain Reflectometer being constructed for data collection and analysis. It also included installation of optical fibers at the test site along an operating pipeline.
\end{abstract}




\section{TABLE OF CONTENTS}

Page

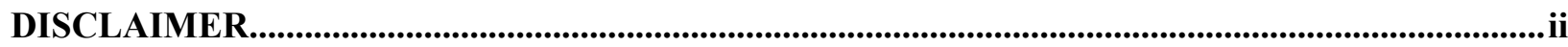

ABSTRACT T

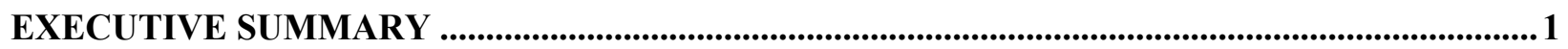

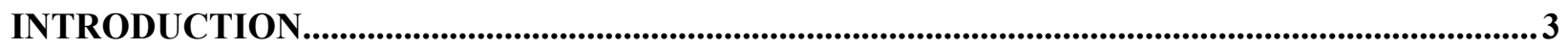

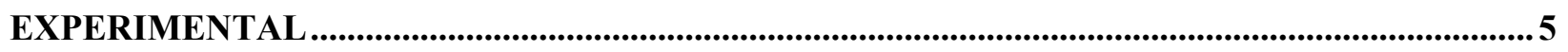

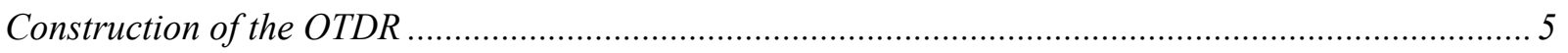

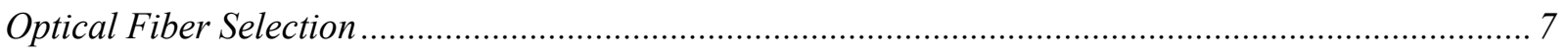

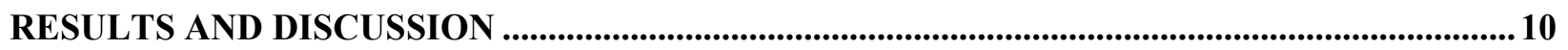

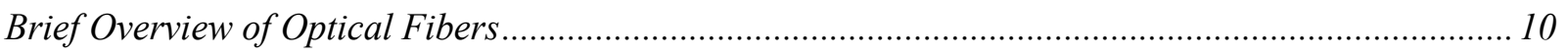

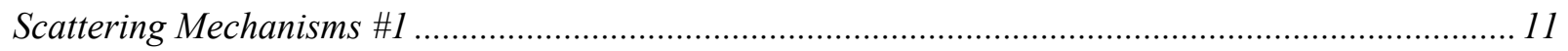

Scattering Mechanisms \#2: Minimum Rayleigh Scattering in a Glass Fiber.................................... 13

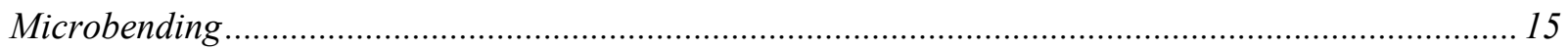

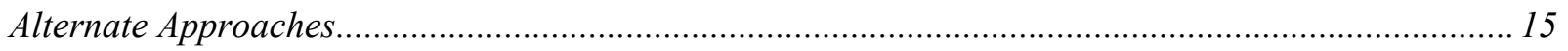

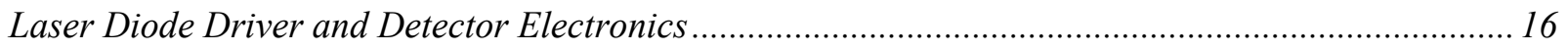

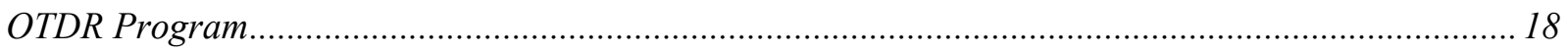

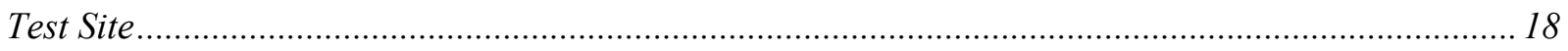

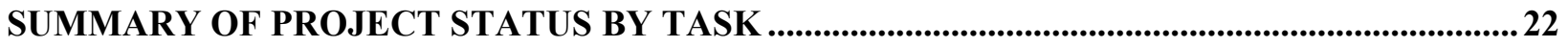

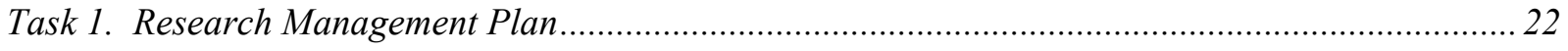

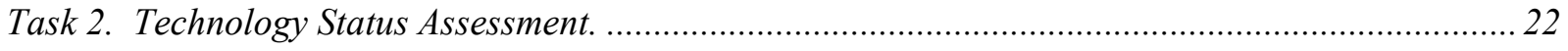

Task 3. Construct and Program Custom OTDR ....................................................................... 22

Task 4. Select, Install, and Test Optical Fiber Cables ................................................................... 23

Task 5. Collect Data on Selected Right-of-Way Encroachment Types ............................................... 23

Task 6: Develop Techniques to Distinguish Potentially Harmful from Harmless Encroachment.......... 23

Task 7. Demonstrate Sensitivity and Discrimination Capabilities ................................................... 24

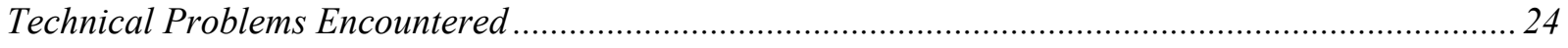

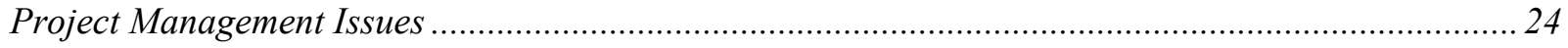

Action Requested of DOE NETL Project Manager.......................................................................... 24 


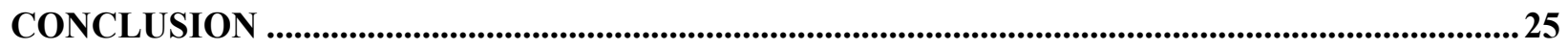

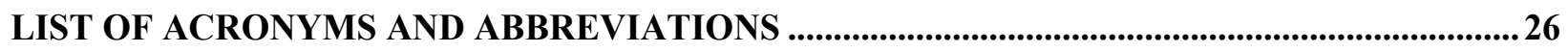

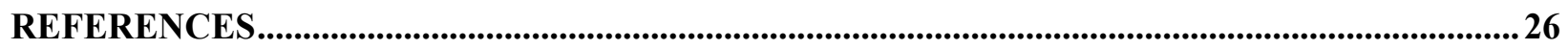

\section{LIST OF GRAPHICAL MATERIALS}

\section{Figure}

Figure 1. SCHEMATIC OF THE CUSTOM OTDR............................................................................................

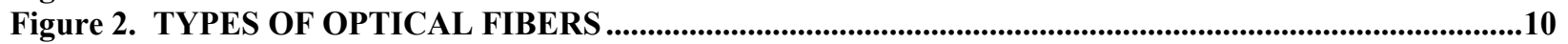

Figure 3. A HIGHER MODE LIGHT WAVE TRAVELS A LONGER DISTANCE.........................................11

Figure 4. PHOTOGRAPH OF THE OTDR CIRCUITRY ......................................................................................17

Figure 5. PHOTOGRAPH OF THE DIGITAL OSCILLOSCOPE AND THE OTDR CIRCUITRY ..............18

Figure 6. AERIAL VIEW OF TEST SITE ............................................................................................................19

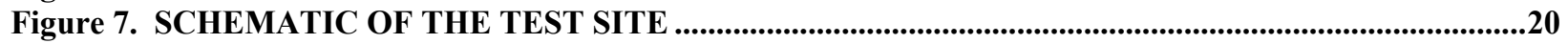




\section{EXECUTIVE SUMMARY}

Natural gas transmission companies mark the right-of-ways where pipelines are buried with warning signs to prevent accidental third-party damage. Nevertheless, pipelines are sometimes damaged by unauthorized construction equipment. A single incident can be devastating, causing death and millions of dollars of property loss. Detection of construction equipment entering a pipeline right-of-way before it can damage the pipeline would greatly reduce $3^{\text {rd }}$-party damage.

Using an optical time domain reflectometer (OTDR) to monitor the light reflection properties of an optical fiber buried near the pipeline can provide continuous monitoring of several miles of pipeline from a single location. A long optical fiber, similar to those used in telephone systems, is buried above the pipeline. Periodically, light pulses are sent down the optical fiber. Normally, little light is reflected back to the source. When construction equipment is present, the ground above the fiber is compressed and vibrated. This changes the optical properties of the fiber and a small portion of the light is reflected back to the source where it is detected.

The location of the equipment is determined by measuring the time for the reflected light pulse to return. (It is not necessary for equipment to break the fiber to be detected.) After the equipment leaves, the optical fiber returns to normal. Because potentially harmful encroachment is rare, methods of distinguishing harmful equipment from benign interferences, such as pedestrians and mowing equipment, are critical.

Because only a small portion of the light is reflected back, most of the light pulse continues along the optical fiber. This means that more than one event (encroachment) can be detected at the same time. This is critical in busy urban areas where encroachments can occur simultaneously along a long optical fiber. This capability also means that the signals from locations at railroad tracks and highways can be distinguished from simultaneously occurring hazardous activities and ignored. In contrast, in some extended optical fiber sensor systems, train and highway traffic dominate the signals and prevent detection of hazardous encroachment.

The project will work to 1.) develop the necessary hardware and demonstrate the ability to detect construction equipment near underground pipelines and 2.) develop methods for distinguishing between potentially hazardous and benign intrusions into the right-of-way. At the end of Phase 1, the Gas Technology Institute (GTI) will demonstrate the ability to detect construction equipment on a pipeline right-of-way and to discriminate among signal sources.

The project began in October 2001. The first order of business was to develop a detailed Research Management Plan for Phase 1 including technical, budgetary, and scheduling aspects. Next a Technology Status Assessment describing the state-of-the art in 3rd-party damage detection and right-of-way-encroachment for use by NETL was written and approved.

In December 2001, our subcontractor, Nicor Technologies (NT), announced their decision to leave the research business. NT was to be the liaison with its sister company Nicor Gas to provide the site for the installation of the optical fibers. As part of the subcontract, NT would have rented the construction equipment and operators for generating encroachment signals. As a result, other arrangements are needed to obtain a suitable site. A site in the 
Chicago area is desired to minimize travel expenses and because the buried fiber will be exposed to a variety of moisture and frozen soil affects. During the $2^{\text {nd }}$ quarter 2002, discussions were held with Nicor Gas on their willingness to participate under a different agreement. Nicor could not provide a transmission pipeline site, however, they were willing to provide a site along a high-pressure distribution pipeline. DOE strongly preferred to have the fiber buried along a transmission line, as the results would have more meaning to transmission companies.

GTI found another company, ANR Pipeline, who operates transmission pipelines in the Chicago area and is willing to provide a site. During the $3^{\text {rd }}$-quarter 2002, GTI visited the probable test site. This site is very suitable. It is within 1.5 hours of GTI and provides easy assess to 110 volt electrical power. It provides areas for testing both over and away from the pipeline.

During the $4^{\text {th }}$ quarter 2002, ANR Pipeline and GTI planned the installation of optical fiber distributed sensors at the site. Due to unusually warm winter weather, it was possible to install the fiber during the week of January 6, 2003.

In order to provide sensitivity to detect the encroachments and to manipulate the data to discriminate among sources, a custom OTDR is required. Commercially available units do not meet our needs. GTI originally planned to use a commercial laser diode driver, but could not find a suitable unit. During the $2^{\text {nd }}$ quarter 2002, GTI designed a laser diode driver and a highspeed amplifier to create and detect the 10-nanosecond long light pulses. Programming of the high-speed, digital oscilloscope forming the heart of the Optical Time Domain Reflectometer (OTDR) is complete.

During the $3^{\text {rd }}$ quarter 2002, GTI constructed the laser driver and high-speed amplifier for the photodetector. Assembly of the circuitry is complete. A key to this technique is substantially increased speed over a conventional OTDR used to test optical communication fiber. This requires special attention to laser stability, detector stability, and instrument noise. The debugging and fine-tuning began to insure the custom OTDR meets the measurement objectives.

During the $4^{\text {th }}$ quarter 2002, the fine-tuning and debugging continued. Several problems were found and traced to discrepancies between the manufacturer's published specifications and the actual performance of the component. Many of these problems have been identified and corrected. However, a few remain and the OTDR is not functioning as expected.

Completion of the OTDR is six months behind schedule. The project is on budget. 


\section{INTRODUCTION}

The overall objective of this project is to develop and demonstrate an optical fiber intrusion detection device that will prevent outside force damage by detecting and alarming when construction equipment is near a pipeline. Such a technology would result in safer and more reliable pipeline systems and solve a long-standing problem of the natural gas industry. Alerting a pipeline company that construction equipment is moving close to its pipe permits immediate action to stop unapproved excavation and potential damage to the pipeline. The proposed system will provide real-time policing of pipelines 24 hours a day, seven days a week. Prevention of third-party damage will reduce public and utility injuries, service interruptions, and repair costs, resulting in a safer, more reliable transmission infrastructure.

Gas transmission pipelines are buried in utility right-of-ways marked with warning signs. These right-of-ways are well maintained. Nevertheless, pipelines are sometimes damaged by construction equipment not owned by the pipeline company. Referred to as third-party damage, it is the major cause of damage to natural gas transmission pipelines (ref. 1). A single incident can be devastating, causing death and millions of dollars in property loss. One highly publicized incident occurred in Edison, NJ, in 1994. Flames shot 125 to 150 meters (400 to 500 feet) into the air near an apartment complex. Nearly 100 people were treated in hospitals as a result of the accident. Damage from the incident exceeded $\$ 25$ million (ref. 2).

A cost-effective, continuous monitoring system is required to prevent third-party damage. "One-call" systems and greater legal penalties have reduced, but not eliminated, the number of

incidents. A backhoe, trencher, or auger (for digging post holes) can move into the right-of-way, begin excavation, and damage the pipeline in less than 30 minutes. A boring machine can travel beneath the surface of the ground for greater than 30 meters. This type of equipment can damage the pipeline without ever having the above ground portion of the equipment in the right-of-way.

The approach is to combine existing technologies in a novel way to achieve the required sensitivity to construction equipment and solve the critical problem of minimizing false positives. The use of an optical fiber strand as a distributed sensor has been investigated for many years. Optical time domain reflectometry (OTDR) is a standard telecommunication industry tool for testing fiber optic cables that are hundreds of kilometers long. GTI demonstrated that a fiber optic system with a commercial OTDR with a long averaging time could detect construction equipment (ref. 3). The ability to bury a fiber optic cable with a vibratory plow has also been demonstrated (ref. 4). A large number of microprocessor-based 
signal processing and recognition techniques exist. Thus, the basic technologies do not need to be developed, but rather modified and extended into a practical system.

Specifically, the technique will use an optical fiber with the techniques of OTDR and signal recognition as a method to provide an alarm when unauthorized construction equipment violates a pipeline right-of-way. The optical fiber would be buried above the pipeline. Light pulses would be periodically sent down the optical fiber. Normally, no construction equipment is near the fiber and little light is reflected back to the source. Construction equipment creates vibrations in the ground. It also causes compression of the soil. When close to the optical fiber, the vibrations and soil compressions stress and/or bend the fiber, changing its light transmission and reflection properties. When this happens, some of the light is reflected back to the source where it is detected. Because the velocity of light in the fiber is known, the location of the piece of equipment is determined by measuring the time for the reflected light pulse to return. It is not necessary for equipment to break the fiber to be detected. The optical fiber returns to normal after the equipment leaves.

While third-party damage can be devastating, it occurs infrequently_much less than one hit per kilometer of pipeline a year. Every year, many intrusions occur in the right-of-way. Any encroachment detection system must be able to distinguish a benign activity from a potentially hazardous one, or the false positive count will be too high and the system will not be accepted.

To be economical, it will be necessary to monitor many kilometers of pipeline from a single location. Such long distances require a method to measure the location of each encroachment and be able to detect and monitor simultaneously occurring encroachments. This is especially true in urban areas where the pipeline passes under railroads and highways. Techniques that monitor the optical fiber as a whole (for example interferometric), can be dominated by signals from a slow moving train and not detect hazardous encroachment.

The largest technical barrier is in developing methods to distinguish and characterize the different signals. Most of these are benign with no possibility of injuring the pipeline. (e.g., mowing the right-of-way, people walking, motorcycle and ATV traffic). In addition, benign background noises (thunder, airplanes) must be distinguished from other sounds. Soil conditions (moisture content and freezing) will vary throughout the year. These variations may affect the signals detected by the optical fiber. Compared to mowing equipment, pedestrians, etc., construction equipment will be large and have characteristic signals. Seasonal and temperature changes will occur slowly and can be eliminated by creating a time-averaged baseline where the time average is long compared to movement of equipment. 


\section{EXPERIMENTAL}

\section{Construction of the OTDR}

In order to collect the required data to detect and then discriminate between encroachments, a custom Optical Time Domain Reflectometer (OTDR) is needed. It must be capable of collecting and storing a waveform digitized as a function of time from each "segment of optical fiber." The resulting time histories from individual "segments" will be used to detect encroachment, characterize signals created by construction equipment and benign background noise, and discriminate signal sources. The segments are created by sending a narrow light pulse ( $\sim 10$ nanoseconds) into the optical fiber and digitizing the returning signal at $100 \mathrm{MHz}$. A typical index of refraction for glass optical fiber is 1.5. Thus, the velocity of light in the fiber is $2 \times 10^{8} \mathrm{~meter} / \mathrm{sec}$. A $100 \mathrm{MHz}$ digitizer collects a data point every 10 nanoseconds. Light travels 2.0 meters in that time. For data analysis purposes, the fiber is divided into two-meter segments, which is approximately the size of a backhoe.

To keep the data analysis speed and memory requirements manageable for the proof-ofconcept, a fiber length of approximately 1.0 kilometer was planned. Five hundred data points (segments) are required to monitor each kilometer of fiber and will take five microseconds (corresponding to the one way roundtrip travel time of one light pulse) to collect. Separating pulses by 10 microseconds or more will keep reflection signals from overlapping. A backhoe moving at 32 kilometers/hr covers 8.9 meters/second. Thus, the high-speed data collection system will be able to collect detailed information on the motion of the backhoe. These arguments can be extended to show that several kilometers could be monitored from one location in a commercial encroachment detection system.

The data collection process can be stated another way. Each light pulse will create a waveform on the digital oscilloscope. The amplitude of this waveform at each point gives information on the activity above that segment of the optical fiber. Collecting a series of waveforms and rearranging the data into amplitude as a function of time for each digitized time increment will give the time history above each segment of the optical fiber.

GTI's technical approach is to purchase and assemble as many commercially available components as possible to construct an OTDR. Most, if not all, of the components-laser diode, sensitive detector, high-speed digitizer and large memory — and a computer system capable of collecting and analyzing the data - are commercially available. 
Components from National Instruments (NI) were selected because of the ease and flexibility of assembly and programming. A digital oscilloscope has been assembled using:

- NI 5112, $100 \mathrm{MHz}, 100 \mathrm{MS} / \mathrm{s} 8$-bit digitizer, dual channel, with $64 \mathrm{MB}$ flash memory

- PXI-1025 Mega PAC rugged portable chassis for PXI cards

- PXI-8170/850 high-performance embedded controller (850 MHz Pentium III) with 256 MB extended memory

A high-speed timing bus on the computer backplane facilitates precise launching and timing of light pulses. GTI's electronic laboratory has all of the tools and equipment needed to assemble the OTDR. GTI has National Instruments' LabVIEW 6.1 Professional Software Package, Hi-Q mathematics package, and Signal Processing Toolset. The latter provides abilities for joint time-frequency analysis and wavelet analysis, which may prove useful in discriminating signals. GTI also has the latest MATLAB with its signal processing toolbox.

Other components in the OTDR include:

1. A stable, repeatable high-speed light source such as a laser diode or LED. Stability is required to eliminate any fluctuations and minimize the amount of normalization to each light pulse. Variations in light intensity would be interpreted as signals. Many diode lasers have a separate output giving the intensity of the pulse which can be used to trigger an oscilloscope and normalize input pulse amplitudes.

2. A highly reproducible pulse generator

3. A stable power supply to drive the light source. It must create light pulses of 10 nanosecond duration with a timing between pulses of $\sim 10$ microseconds.

4. A stable, high-speed detector with a dynamic range large enough to detect backscattered signals from the stressed portions of the fiber

5. Low noise amplifier and band-pass filter to amplify the signals from each detector

6. An optical coupler to inject the pulse from the light source into the optical fiber with minimal light transferring directly to the returning pulse detector. The coupler also splits the returning light pulse in two, permitting its detection.

7. Attenuator at the end of the fiber to minimize the amplitude of the reflected signal

8. Low-loss connectors 
Figure 1 is a schematic of the custom OTDR showing the critical components. The requirements for each component are known. Specific parts have been selected and ordered.

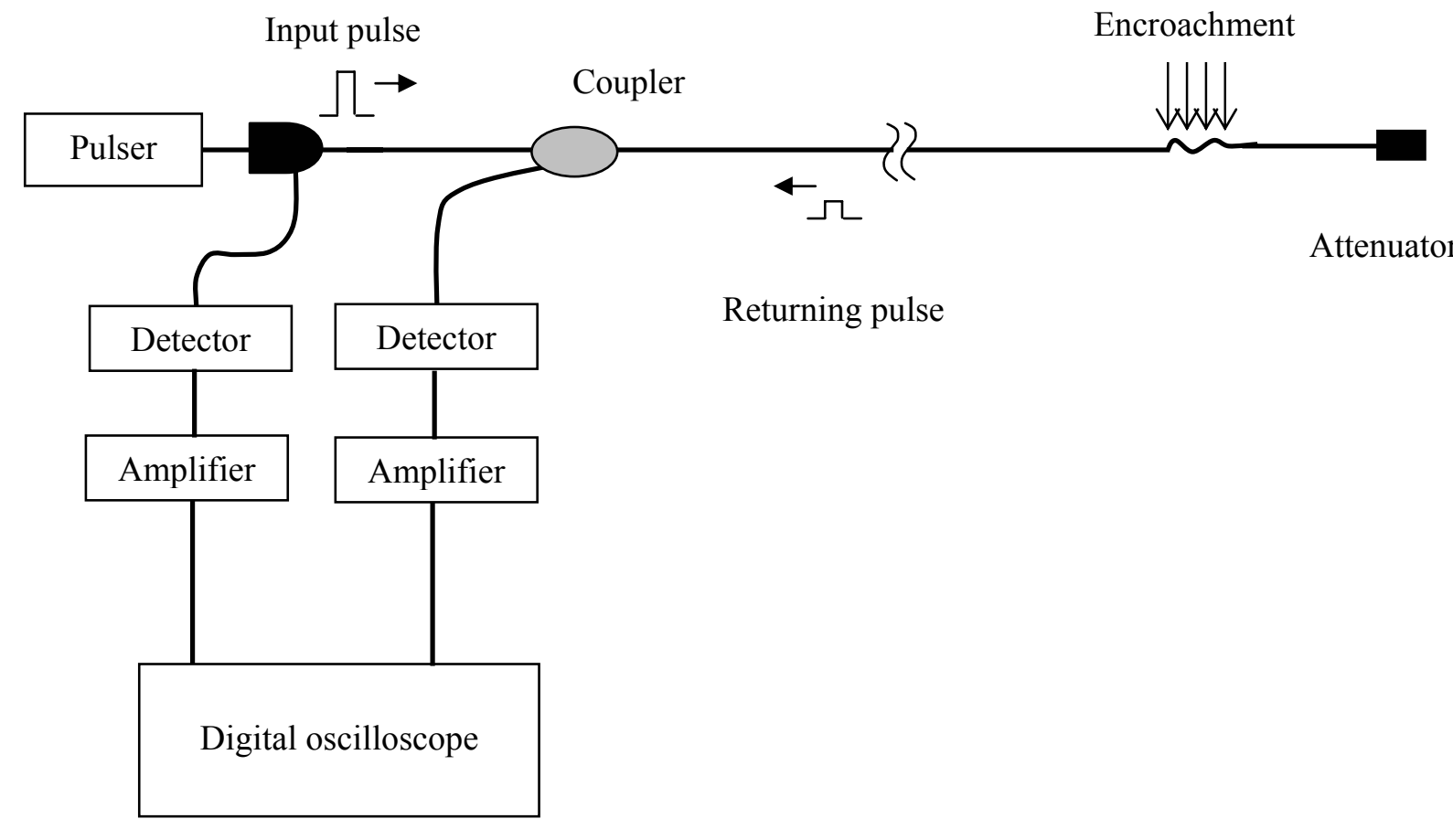

FIGURE 1. SCHEMATIC OF THE CUSTOM OTDR

\section{Optical Fiber Selection}

An important component of the detection system is the choice of the optical fiber used as the sensor and its environmental shielding. The goal is to have an optical fiber that is sensitive to stress and vibrations at an affordable price. Environmentally, the cable must be impervious to water (to avoid degrading fiber properties), non-electrically conducting (to avoid damage from lightning strikes), and resistive to abrasion (being chewed by rodents, etc.). At the same time the environmental sheath must not make the system insensitive to the vibrations and stresses being measured. Part of the project is to evaluate optical fiber sensitivity and durability.

Cable lengths above the transmission pipeline site will be approximately 1 kilometer. This length will permit testing of spatial and time resolution, sensitivity to various encroachments and the ability to detect and discriminate among simultaneous events, while limiting the initial signal processing and memory storage requirements of the OTDR. One site selection criteria is the ability to leave the fiber in place for several years with access by GTI. 
The first step in fiber selection was to review the mechanisms that reflect light back to the OTDR, especially those sensitive to stress and vibration. This discussion is given in the section on Results and Discussion. The next step was to compare our needs to commercially available products.

Optical fibers are commercially available because of the telecommunication market. The focus of that market is faster data transmission rates and, therefore, fibers with less sensitivity to stress, strain, and vibration. The optical fiber manufacturers work hard to minimize sensitivity to vibration and stress. They prominently mention this in their advertising. Our application calls for fiber that is sensitive to vibrations. The knowledge of how to minimize sensitivity to stress and vibration implies the knowledge to make a better sensor. This issue was discussed with several fiber manufacturers and suppliers at the Optical Fiber Conference in Anaheim the week of March 18, 2002. No one admits to having fiber that is more sensitive to vibrations. A few are thinking of making distributed sensors — but the market size appears too small for much enthusiasm on their part.

Four fibers were selected as candidates as the optical fiber sensor. The initial goal is to demonstrate the ability to detect encroachment. Choices of fibers were made primarily on the prospects for good sensitivity. The fibers and the reasons for there selection are given below.

A version of Hergalite, a multi-mode optical fiber (50 $\mu \mathrm{m}$ core/125 $\mu \mathrm{m}$ cladding) spirally wound with wire, has been purchased and delivered. When stress is applied to the cable, the spiral wound plastic fiber increases the microbending in the optical fiber. This type of fiber was used in the project that detected a rubber-tired backhoe with a low-cost OTDR. Three hundred meters has been purchased at a cost of $\$ 1.20$ per meter. (The manufacturer cautions against its use in areas where easy access to the cable is difficult, such as buried pipe, because the wire can be permanently deformed. When the set is permanent - the wire doesn't return to its original position when the load is gone. It is possible that the amount of loading of buried Hergalite is too small to cause a permanent set.)

A single mode fiber was obtained from Fibercore Limited. SM600 has a wavelength design frequency of $\sim 650 \mathrm{~nm}$, meaning that wavelengths of $650 \mathrm{~nm}$ or longer will propagate as a single mode. This feature will permit using a range of wavelengths in single mode to adjust the amplitude of Rayleigh backscattering (Rayleigh backscattering increases with shorter wavelengths). This fiber has a core surrounded by a cladding $(125 \mu \mathrm{m})$ and a "single acrylate coating," making the fiber diameter $250 \mu \mathrm{m}$. This fiber has a numerical aperture of $0.10-0.14$. The price for SM600 is $\$ 2.36$ per meter for lengths of 1.0 kilometer or more. Cabling for 
moisture protection is extra. A source of jacketed Fibercore SM600 was found, however, it is too expensive to be practical. It was not purchased.

The third optical fiber that will be tested, Corning ${ }^{\circledR} 62.5 / 125$, is part of Corning's line of standard multimode fibers. It is inexpensive at $\$ 0.15$ foot when incased in a $2.9 \mathrm{~mm}$ diameter jacket.

A multimode fiber, with a core diameter of $200 \mu \mathrm{m}$ was also selected. The larger diameter should make this fiber more sensitive to mode conversion during vibration and stress. This feature will permit using a range of wavelengths in multi-mode. The manufacturer has been unresponsive to providing pricing and delivery times. This fiber was replaced with Corning® $50 / 125$, which is similar to the optical fiber in the Hergalite - permitting a determination of the effectiveness of the stress increasing fiber.

Other potential candidates are Corning ${ }^{\circledR}$ PureMode ${ }^{\mathrm{TM}}$ HI 980, Corning ${ }^{\circledR} \mathrm{SMF}-28^{\mathrm{TM}}$ is a single mode fiber, and a polarization maintaining fiber.

Corning ${ }^{\circledR}$ PureMode ${ }^{\mathrm{TM}}$ HI 980 is a single mode fiber at wavelengths of $980 \mathrm{~nm}$ and longer. It has a numerical aperture of 0.20. Corning advertises this fiber as "offering reduced bend attenuation due to its high core index of refraction." It has the least attenuation of the fibers under consideration. This fiber is $\$ 3.25$ per meter in lengths of 1.0 kilometer or more. Water resistant coating and connectors are extra.

Corning ${ }^{\circledR}$ SMF $-28^{\mathrm{TM}}$ is a single mode fiber commonly used in the telecommunications industry. It is optimized for use in the $1310 \mathrm{~nm}$ window. Its chief advantages are its low attenuation and low price.

Other possibility is a polarization maintaining fiber. Corning makes a number of them with a range of cutoff wavelengths. Light propagates in two perpendicular polarizations. Polarization maintaining fibers are pre-stressed so that the two polarizations travel independently with minimum cross talk. If the fiber is stressed some conversion from one polarization to the other occurs. If light of a single polarization is used, any light of perpendicular polarization indicates stress. The other fibers will be tried first. 


\section{RESULTS AND DISCUSSION}

\section{Brief Overview of Optical Fibers}

Optical fibers are made from two transparent materials; usually glass, with differing indices of refraction. Index of refraction is the ratio of the speed of light in a vacuum to the speed of light in the material. An optical fiber is formed when a thin core of index $n_{1}$ is surrounded by an outer core (cladding) of index $\mathrm{n}_{2}$. If the cladding has a smaller index of refraction, and the light is incident on the interface between the two materials at an angle less than the critical angle, total internal reflection occurs. This creates an optical waveguide. Little energy is lost from the light beam and the beam can propagate for long distances. A thin buffer is often added around the cladding to provide waterproofing and additional jacketing materials are available.
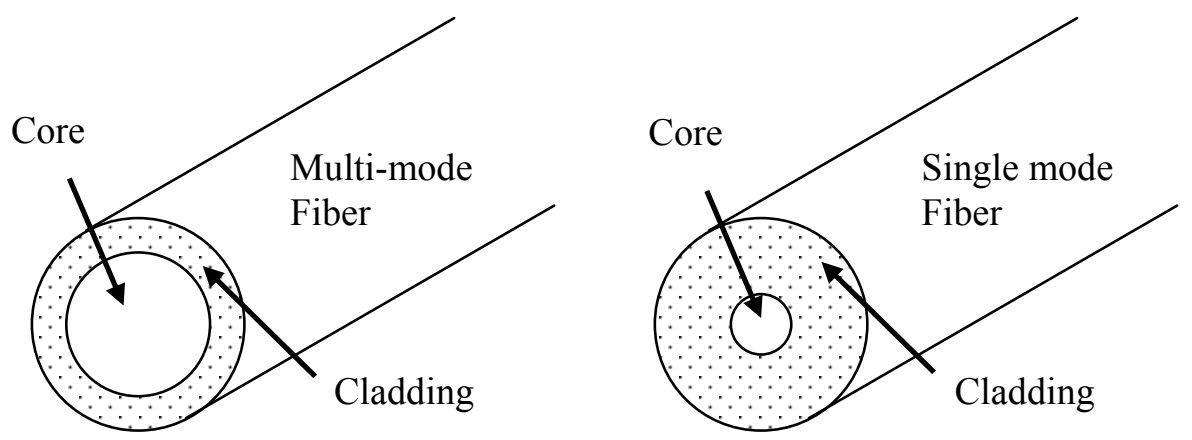

FIGURE 2. TYPES OF OPTICAL FIBERS

There are two general fiber configurations: single mode and multi-mode. As shown in Figure 2, a single mode fiber the core is smaller in diameter than a multi-mode fiber core. In either case, the outside cladding diameters of single- and multi-mode fibers are typically 125 micrometers (or about the size of the human hair). Light may enter a multi-mode fiber at several angles. Some of this light will travel in the waveguide with a minimum of reflections from the core/cladding interface. Light entering at a greater angle will also propagate in the waveguide by making more reflections (higher modes). Because of the extra reflections, the higher modes must travel a greater distance and take longer to transverse the optical fiber (See Figure 3). In order to propagate in a single mode fiber, the light wave must enter the fiber nearly parallel to the axis of the fiber. Multi-mode fiber will carry more light than single-mode. On the other hand, if a pulse of light is injected into a multi-mode fiber and the fiber is bent, mode conversion 
will occur, both attenuating and broadening the pulse. Mode conversion occurs when some of the light is changed from a mode with few reflections to a mode with more reflections.

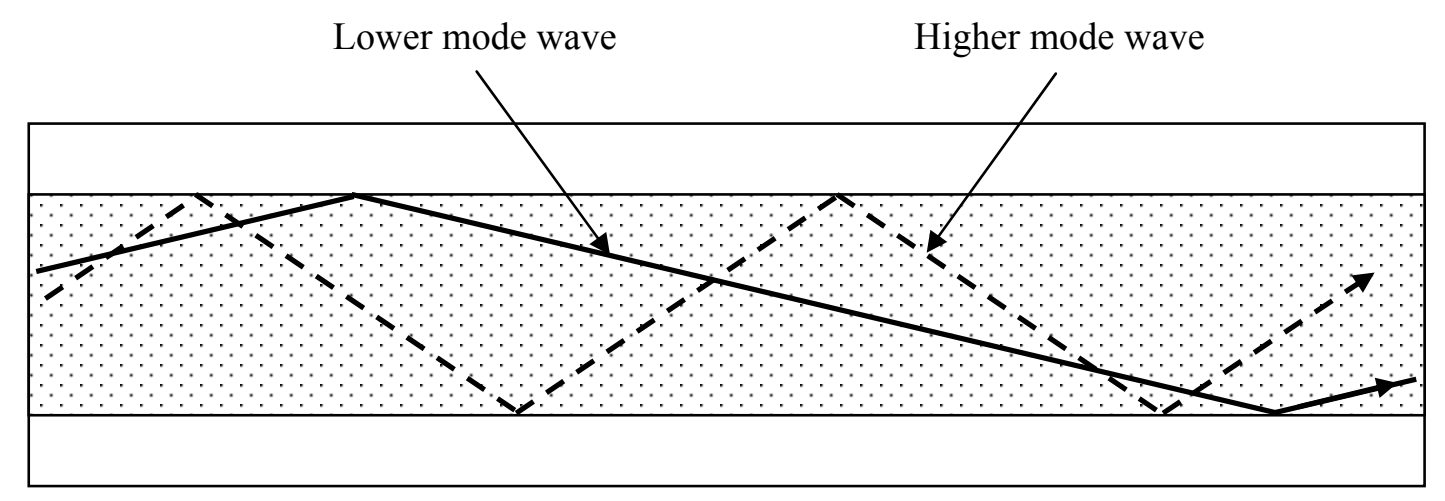

FIGURE 3. A HIGHER MODE LIGHT WAVE TRAVELS A LONGER DISTANCE

Mode conversion can be effective as a sensing mechanism. A continuous light wave can be sent into a fiber and the total light intensity measured as a function of time. If mode conversion occurs because of stresses to the fiber and microbending, variations will be produced in the outputs that are proportional to the vibrations of the fiber. This is used as a stress measurement technique. Unfortunately, for our application, changes everywhere along the fiber are measured simultaneously. In the encroachment monitoring application with fiber lengths of a few miles, multiple events (disturbances to the fiber) will occur simultaneously. The use of OTDR has the potential to independently monitor the simultaneous vibrations.

\section{$\underline{\text { Scattering Mechanisms \#1 }}$}

Light is attenuated as it travels down a fiber by several mechanisms. These processes include bending of the optical fiber and scattering mechanisms. A scattering mechanism absorbs the incoming light and reemits it at all angles. Light reemitted at right angles to the incoming beam will be lost into the cladding. Some of the light is reemitted backwards and returns to the light source. Our approach is to use the phenomenon of backscattering to detect stress to and vibration of the fiber.

Much of the scattering in an optical fiber is caused by variations in the density of the fiber. Variations in density change the velocity of light and thus the index of refraction. Unintentional density variations are built into the fiber during its manufacture. These are caused primarily by thermal fluctuations in density and variations in the concentration of dopant materials just before the glass transitions into a solid. The predominant use of optical fibers is in 
telecommunication. Thus, the fiber manufacturer tries to minimize scattering losses because they increase the attenuation in the fiber and thereby limit the distance a signal can be sent.

Stress, vibrations, temperature change, and acoustic waves induce other density variations. The scattering induced by the density fluctuations can be elastic (no change in the wavelength between the incoming and outgoing light wave) or inelastic (a shift in the wavelength between the incoming and outgoing light wave).

Rayleigh scattering often refers to the scattering of light by air molecules. However the term also applies to scattering from particles up to about a tenth of the wavelength of the light. (Green light has a wavelength of $\sim 550$ nanometers. Rayleigh scattering off the molecules in air creates the blue sky.) It is elastic because energy of the scattered wave is the same as the incident wave. Lord Rayleigh modeled the air molecule as an electric dipole driven by the electric field of the light wave. The scattered intensity from dipole scatterers much smaller than the wavelength of light ( $\operatorname{ref} 5)$ is:

$$
\mathrm{I}=\mathrm{I}_{0} 8 \pi^{4} \mathrm{~N} \mathrm{p}^{2}\left(1+\cos ^{2} 2 \theta\right) /\left(\mathrm{R}^{2} \lambda^{4}\right)
$$

where $\mathrm{N}=$ number of scatterers, $\mathrm{p}=$ polarizability, $\mathrm{R}=$ distance from the scatterer, $\lambda=$ wavelength of the light, $\theta=$ angle of the scattered light with respect to the incoming light. Note that light is scattered in all directions, including directly back on the incoming light.

Equation 1 is for air molecules. Changing the geometry to backscattering in an optical fiber, the attenuation, $\alpha$, caused by Rayleigh scattering is given by (ref 6)

$$
\alpha=8 \pi^{3}\left(\mathrm{n}^{2}-1\right) \mathrm{kT} \beta /\left(3 \lambda^{4}\right) \quad \text { eq. } 2 .
$$

where $\beta=$ isothermal compressibility of the glass, $\mathrm{T}=$ temperature. For fused silica transitioning at $1500^{\circ} \mathrm{C}$, this represents a loss of $1.7 \mathrm{~dB} / \mathrm{km}$ at $820 \mathrm{~nm}$.

Although equation 2 gives the total attenuation, part of the backscattered light propagates back through the waveguide. The important features to note are the temperature dependence of the backscattering and the very strong wavelength dependence, $\lambda^{4}$. Decreasing the wavelength by a factor of two, increases the Rayleigh scattering by a factor of 16 . Therefore we can adjust the amount of backscattering by the choice of the light source.

For many fiber optic sensor applications, Rayleigh scattering dominates. However, it is also possible to detect light from Raman and Brillouin scattering.

Brillouin scattering is the scattering of light from sound waves in the fiber. From the classical point of view, the acoustic waves locally change the density-i.e. the refraction and 
compression of the material. From the quantum point of view, the light photons interact with the acoustic or vibrational quanta (phonons). Brillouin scattering is inelastic with energy being gained or lost by the interaction with the moving sound wave. The shift in frequency is small and Brillouin light is difficult to separate from Rayleigh scattering. However, it can be separated from the original wavelength with special instrumentation. Brillouin scattering can be used to measure stress in the optical fiber. Ando Corporation makes an Optical Fiber Strain Analyzer, model AQ8603. It is a sophisticated OTDR and costs $\sim \$ 130,000$. Each data trace requires 2 minutes to collect, making it too slow to characterize encroachment signal. Ando demonstrated this unit at GTI.

Raman scattering, like Rayleigh scattering, depends on the polarizability of the molecules. For polarizable molecules, the incoming light wave (photons) can excite vibrational modes of the molecules, yielding scattered photons that are diminished in energy by the amount of the vibrational transition energies. Because there can be many vibrational modes in a molecule, a spectrum of Raman scattering yields a series of lines at lower frequencies (longer wavelengths) than the incoming light. Such lines are called "Stokes lines." If there is significant excitation of the vibrational excited states, then it is also possible to detect scattering at higher frequencies. These spectral lines are called "anti-Stokes lines." Anti-Stokes lines are normally weaker than Stokes lines. The anti-Stokes lines are a sensitive indicator of temperature. Raman scattering is much weaker than Rayleigh scattering. Raman backscattering can be separated from Rayleigh and Brillouin scattering to improve the signal to noise ratio.

Because of the extra complexities and cost required to detect Raman and Brillouin scattering, GTI will use microbending and/or Rayleigh scattering to detect encroachment.

There are several other phenomenon and measurement techniques (mostly discrete sensors) that have the potential of measuring stress and vibrations. As in the case of Raman and Brillouin, the added complexity is not justified for our application. Thus they have not been described.

\section{Scattering Mechanisms \#2: Minimum Rayleigh Scattering in a Glass Fiber.}

A second treatment of Rayleigh scattering was found that gives the theoretical minimum possible amount of Rayleigh scattering in glass optical fibers. Many commercial optical fibers are close to this limit. The advantage of this analysis is it gives the minimum signal level we must be able to detect. Which in turn provides guidance on the light source wavelength and power level and on the detector sensitivity. 
John M. Senior, Optical Fiber Communications, Prentice/Hall International 1985, pp 6970 gives an equation giving the minimum Rayleigh scattering coefficient as:

$$
\gamma_{\mathrm{R}}=8 \pi^{3} \mathrm{n}^{8} \mathrm{p}^{2} \beta_{\mathrm{c}} \mathrm{k} \mathrm{T}_{\mathrm{F}} / 3 \lambda^{4}
$$

where-

$\gamma_{\mathrm{R}}=$ Rayleigh scattering coefficient

$\mathrm{n}=$ index of refraction of the fiber core [1.46]

$\mathrm{p}=$ average photoelastic coefficient [0.286]

$\beta_{\mathrm{c}}=$ isothermal compressibility at a fictive temperature $T_{\mathrm{F}}\left[7 \times 10^{-11} \mathrm{~m}^{2} \mathrm{~N}^{-1}\right]$

$\mathrm{k}=$ Boltzmann's constant $\left[1.381 \times 10^{-23} \mathrm{~J} \mathrm{~K}^{-1}\right]$

$\mathrm{T}_{\mathrm{F}}=$ The fictive temperature, which is the temperature at which the glass can reach a state of thermal equilibrium and is closely related to the anneal temperature. [1400 K]

$\lambda=$ Wavelength of the incident light.

Note: The values in [] are for silica glass.

This scattering is caused by index fluctuations caused by the freezing-in of density inhomogeneities. The inhomogeneities are fundamental and cannot be avoided. Substituting the values for silica glass into equation 1 gives:

$$
\gamma_{\mathrm{R}}=1.895 \times 10^{-28} / \lambda^{4} \mathrm{~m}^{-1}
$$

The Rayleigh scattering coefficient is related to the transmission loss factor, $\xi$

$$
\xi=\exp \left(-\gamma_{\mathrm{R}} \mathrm{L}\right)
$$

where $\mathrm{L}=$ length of the fiber. The attenuation due to Rayleigh scattering in $\mathrm{dB} \mathrm{km}^{-1}$ is given by:

$$
\text { Attenuation }=10 \log _{10}(1 / \xi)
$$

For example at a wavelength of $0.63 \mu \mathrm{m}, \gamma_{\mathrm{R}}=1.199 \times 10-3 \mathrm{~m}^{-1}, \xi=0.301$, and the attenuation, $\alpha_{\mathrm{R}},=5.2 \mathrm{~dB} \mathrm{~km}^{-1}$

The attenuation can also be expressed as $\alpha_{\mathrm{R}}=10 \log 10\left(\mathrm{P}_{\mathrm{i}} / \mathrm{P}_{\mathrm{o}}\right) . \mathrm{P}_{\mathrm{i}}$ is the input light power (watts) and $\mathrm{P}_{\mathrm{o}}$ is the output light power at the end of the fiber. For 2.0 meters of fiber and a wavelength of $0.63 \mu \mathrm{m}$

$$
\mathrm{P}_{\mathrm{o}}=\mathrm{P}_{\mathrm{i}} 10^{-\alpha \mathrm{R} / 10}=\mathrm{P}_{\mathrm{i}} 10^{-5.2 \times 0.002 / 10} \mathrm{P}_{\mathrm{i}} 10^{-0.00104}=0.997608 \mathrm{P}_{\mathrm{i}}
$$

The amount of scattered light in a 2.0 meter section of fiber is $(1-0.997608) \mathrm{P}_{\mathrm{i}}=0.0024 \mathrm{P}_{\mathrm{i}}$. This value gives the upper limit on the minimum backscattered light because only part of the light is scattered into the fiber. For a fiber with a core index of $n=1.46$ and a cladding index of 1.40 , the critical angle is $\theta=\arcsin (1.40 / 1.46)=73.5$ degrees as measured from the normal to the 
core/cladding interface. $90-73.5$ degrees $=16.5$ degrees. Using the angular dependence in equation 1 , about $10 \%$ of the Rayleigh scattering is reflected back to the source.

Therefore, for a fiber with the lowest loss Rayleigh scattering at $0.63 \mu \mathrm{m}$ and a 2 -meter section of glass fiber, 0.00024 of the input power is reflected back to the source. If the input power (light) is $100 \mu$ watts, $0.024 \mu$ watts (24 nanowatts) will be reflected back. Detectors can measure down to a several hundred nanowatts of light power. This information will be used to select the power output of the light sources.

The diode laser we purchased has a wavelength of $0.69 \mu \mathrm{m}(690 \mathrm{~nm})$ and a light power output into the optical fiber of $10.5 \mathrm{~mW}$. Using the same calculations corrected for the different wavelength of the purchased laser and a 2-meter section of glass fiber, the estimated power reflected back to the source is $\mathrm{P}_{\mathrm{o}}=0.00024 \times 0.69 \mathrm{P}_{\mathrm{i}}=0.00017 \mathrm{P}_{\mathrm{i}}$. The diode laser has an output power of $10.5 \mathrm{~mW}$, thus the reflected power with no extra stress is $\sim 1.75 \mu \mathrm{W}$. Reducing this value for other losses in the OTDR should result in a very detectable signal for the minimum Rayleigh backscattering. Stress related backscatter will be in addition to this value. Because the amplitudes of both the intrinsic and stress/vibration induced backscatter are a function of wavelength, a relatively short wavelength $(690 \mathrm{~nm})$ was selected to maximize the signals.

As described above, Rayleigh backscattering is sensitive to wavelength, with more scattering from shorter wavelengths. Shorter wavelengths also mean more attenuation. Therefore we will have to make tradeoffs between sensitivity and range.

\section{$\underline{\text { Microbending }}$}

Microbending is another method of changing the transmission properties of an optical fiber. In microbending, the curvature of the optical fiber is increased over short distances. This causes some of the light to exceed the critical angle (sometimes as the result of multiple reflections). This results in an increased loss of light in the optical fiber that can be detected by a reduction in the light backscattered from further along the fiber. Wrapping a fiber with a wire or using a fiber with periodic variations in the core diameter can increase the amount of microbending.

\section{Alternate Approaches}

Two commercial products are available for measuring the stress/vibrations in an optical fiber. One is Ando Corporation's Brillouin scattering Optical Fiber Strain Analyzer, model 
AQ8603. It takes 2 minutes to collect a reading, which is too slow for characterizing encroachment types. This equipment is expensive, costing $\sim \$ 140,000$.

Future Fiber Technologies is marketing an optical fiber sensor technology for use in monitoring disturbances to optical fibers. One application is for right-of-way encroachment detection. Based on FFT's Australian patents, the technique monitors the entire fiber by injecting a continuous light source into the fiber and utilizing mode conversion of light at locations where there is a disturbance. Disturbances to the fiber cause some of the light to change modes. Different modes travel at different velocities. When recombined at the detector, the modes interfere causing voltage fluctuations related to the vibrations. The total amplitude is monitored as a function of time in the frequency range of 0 to $100,000 \mathrm{~Hz}$. The major drawback to this technology is it does not separate or distinguish simultaneous events. If we monitor kilometers of pipeline in noisy environments from one location, this will be an issue because of the non-hazardous encroachments and passage near railroads and highways. A second technique, requiring access to both ends of the fiber is used to locate the dominant signal.

\section{$\underline{\text { Laser Diode Driver and Detector Electronics }}$}

The detection approach sends a 10-nanosecond light pulse into the optical fiber every 10 microseconds and digitizes the returning signal at $100 \mathrm{MHz}$. A stable, repeatable light source is required to eliminate any fluctuations in the light pulses that might be interpretated as signals. A $690 \mathrm{~nm}$ diode laser with attached optical fiber was purchased from OECA (Opto-Elektroniscke Componenten und Applikations GMBH) as the light source. It can deliver $10.5 \mathrm{~mW}$ of continuous light power into the fiber. We designed circuitry to create repeatable pulses for driving the diode laser. Because the amplitude of the power output and the lasing frequency are temperature dependant, precautions were taken to deliver a stable pulse. The pulse width can be varied from 8 to 20 nanoseconds. The repetition time between pulses can be varied between 300 nanoseconds and 600 microseconds. The diode laser can also operate continuously. The bias current to the laser can be adjusted to just under the lasing threshold. This keeps fluctuations in the current draw and, therefore, the operating temperature of the electronics to a minimum. The diode laser is mounted on a copper heat sink that is temperature controlled with a thermoelectric module. A $10 \mathrm{~K} \Omega$ thermistor is mounted on the heat sink and will be used in conjunction with an automatic "ultrastable thermoelectric controller" to maintain the temperature to within \pm 0.01 ${ }^{\circ} \mathrm{F}$. A second thermistor will be used to adjust the temperature and verify the actual temperature fluctuations. This electronics can be used to drive diode lasers with other wavelengths. 
A stable, high-speed detector with a dynamic range large enough to detect light scattered from the stressed portions of the fiber is also needed. Silicon photodiodes (FCI-HR005 and FCI-HR008 from OSI Fibercomm) were selected as the detector. Two high-speed amplifiers were designed. One will amplify the output from the photodiode built into the diode laser. The second will amplify the signal from the detector photodiode, which in turn will be feed into the digital oscilloscope. The photodiodes are also mounted on the temperature-controlled heat sink.

The electronics is mounted on a custom printed circuit board in an enclosed electrical box. Figure 4 is a photograph of the laser diode drive circuitry and the photodiode detector circuitry. Figure 5 is a photograph of the digital oscilloscope and the laser diode drive circuitry and the photodiode detector circuitry.

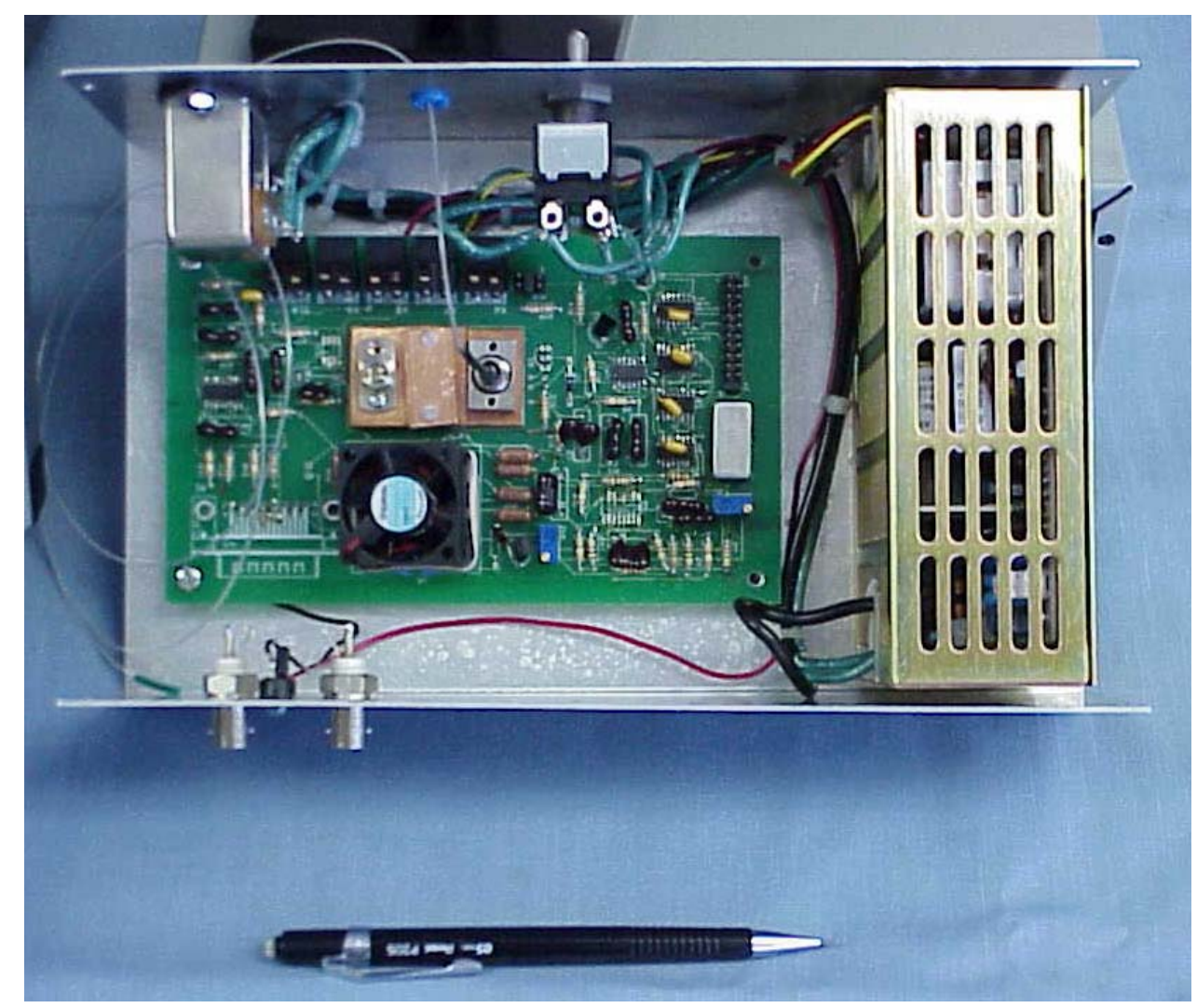

FIGURE 4. PHOTOGRAPH OF THE OTDR CIRCUITRY. 


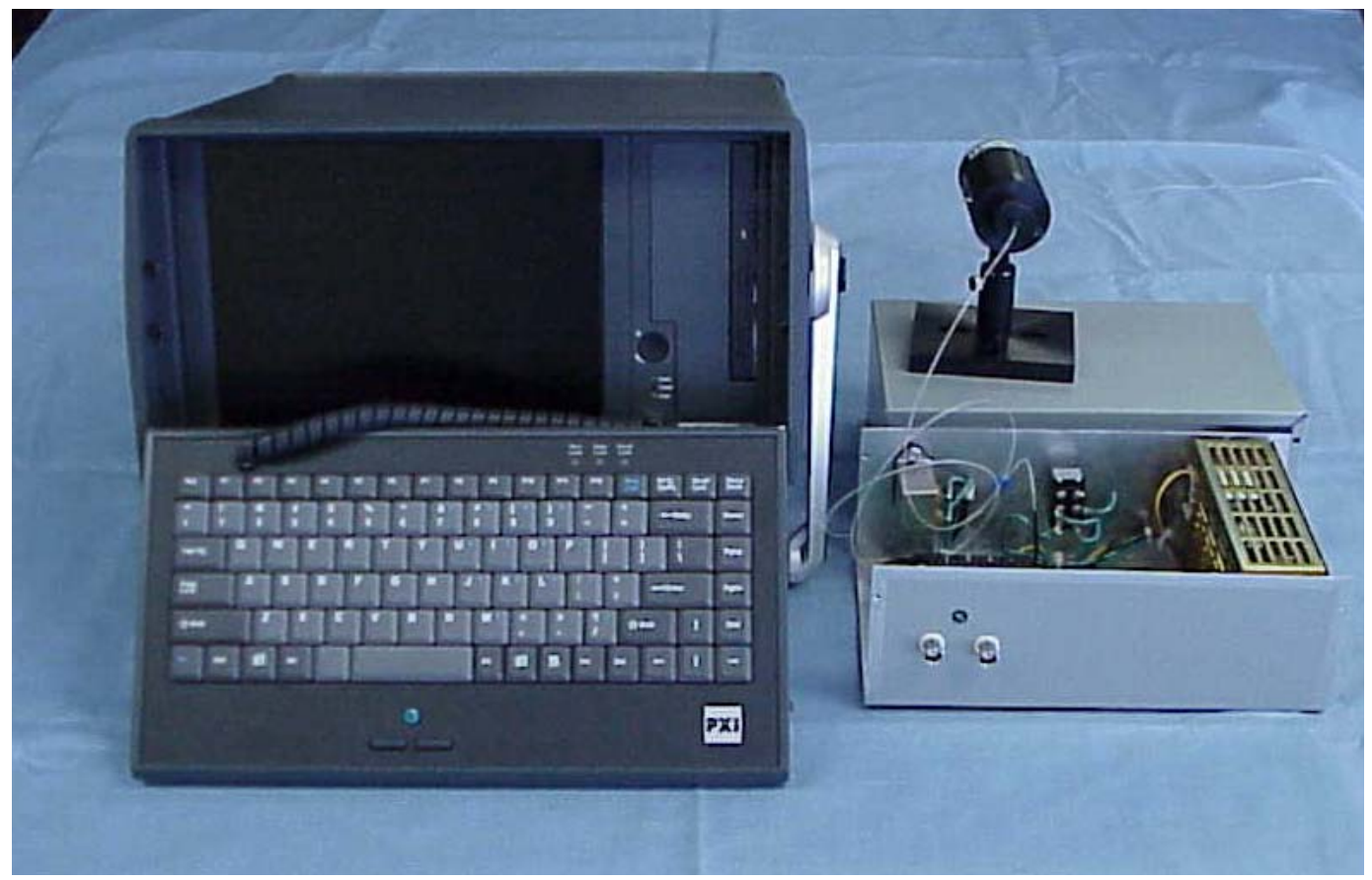

FIGURE 5. PHOTOGRAPH OF THE DIGITAL OSCILLOSCOPE AND THE OTDR CIRCUITRY.

\section{OTDR Program}

The function of the OTDR is to collect data generated by encroachment from the optical fiber over the pipeline. Conceptually, the fiber is divided into 2-meter long segments. The resulting time histories from individual segments will be used to detect encroachment, characterize signals created by construction equipment and benign background noise, and discriminate signal sources. The digital oscilloscope was programmed in National Instruments LabVIEW 6.0 to collect the data as amplitude versus time as the returning backscattered light returns from along the fiber. This results in a series of traces, one for each light pulse spaced 10 microseconds apart. The custom OTDR permits monitoring the data corresponding to each twometer segment as a function of time. This data is stored for later analysis.

\section{$\underline{\text { Test Site }}$}

The OTDR and optical fiber system will be tested in the field at an operating pipeline. ANR Pipeline, Division of El Paso Energy Corporation, is providing the site. Figure 6 is an aerial photograph of the site. The site is along two operating transmission pipelines. One pipeline is 22 inches in diameter; the second is 30 inches in diameter. Overall dimensions of the site are 1430 by 2650 feet. Part of site is under cultivation, part is wooded, part is in open field, and part has a stream running through it. The path of the optical fiber sensors is in both the 
farmed and unfarmed areas. The path of the transmission lines is shown by the green dotted line superimposed on Figure 6. Electrical power is available at the microwave tower located at the end of the gravel road. Instrumentation will be attached to each fiber during the testing and removed between test days.

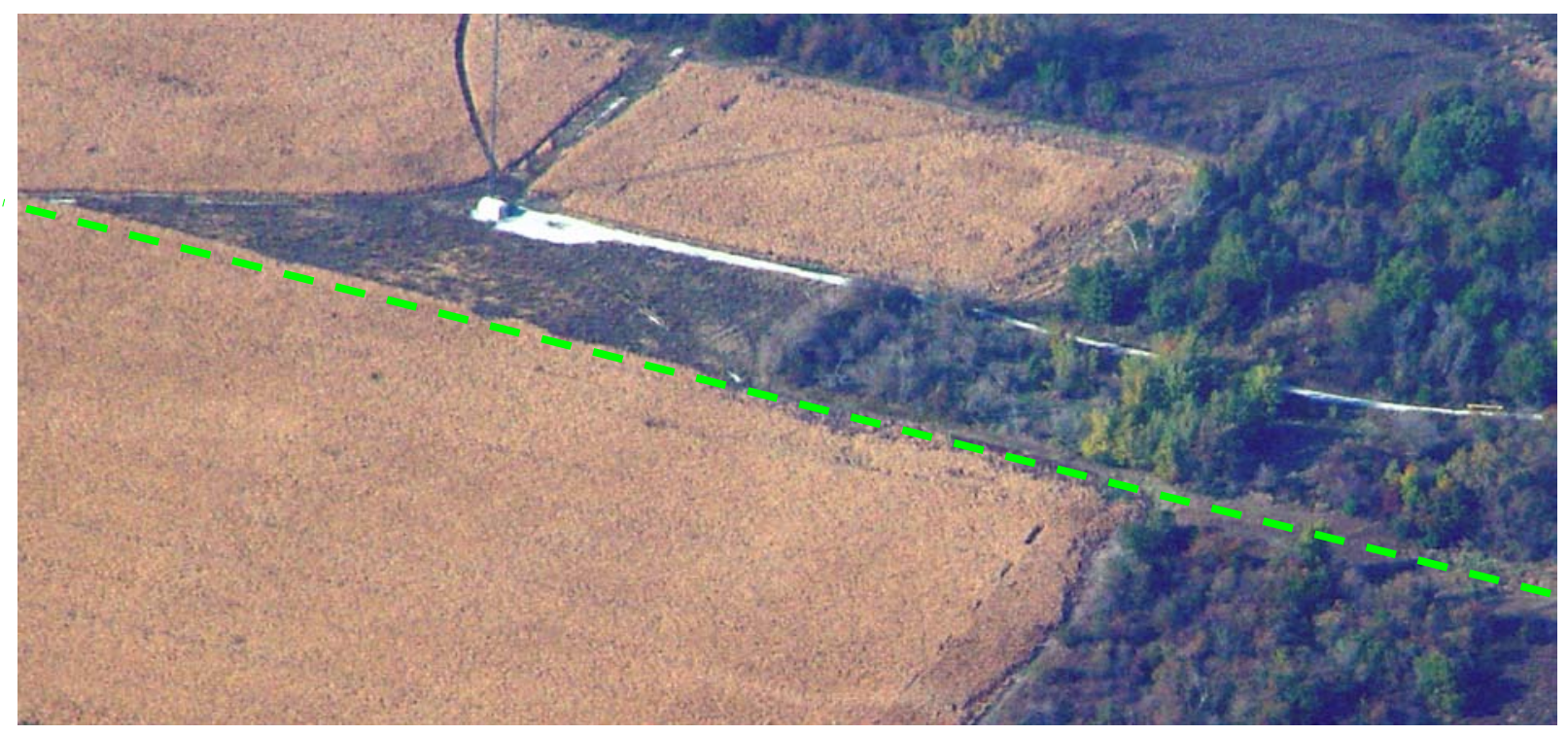

FIGURE 6. AERIAL VIEW OF TEST SITE

Figure 7 is a schematic of the test site using the distances and depths measured when the optical fiber sensors were installed. The red dots in Figure 7 and the corresponding numbers give a running distance from the fence around the microwave tower. We made some modifications to the original plan based on the dimensions of the site. These will give us extra flexibility. The fibers run in a loop from the tower along the gravel road, across the open area, then back along the pipeline at the edge of the cultivated field and back across the field to the microwave tower. Two electrical boxes were mounted on the fence surrounding the microwave tower. A Corning ${ }^{\circledR} 62.5 / 125$ fiber was installed as a loop, with end in each of the electrical boxes. A 543-foot section (between points 887 and 1430 feet) is buried 24 inches directly above the 30 -inch pipeline. A second piece of Corning ${ }^{\circledR} 62.5 / 125$ was installed $1 / 2$ of the way around the loop ( 0 to 887 feet). The latter fiber crossed over the 22 -inch pipe, stopping short of the 30-inch pipeline. The fiber was coiled and 100-foot length of bare Fibercore SM600 was spliced to the end. The last 50 feet of the Fibercore was formed into a 6-inch diameter coil and the tail end brought above the ground (near the 826 foot mark). The end coil provides extra distance so that the end of the fiber is not at the end of the path length. Similarly, $1 \frac{1}{2}$ loops of the Corning ${ }^{\circledR}$ 50/125 was also installed. Two sections of Hergalite were spliced into the Corning ${ }^{\circledR}$ 50/125. 


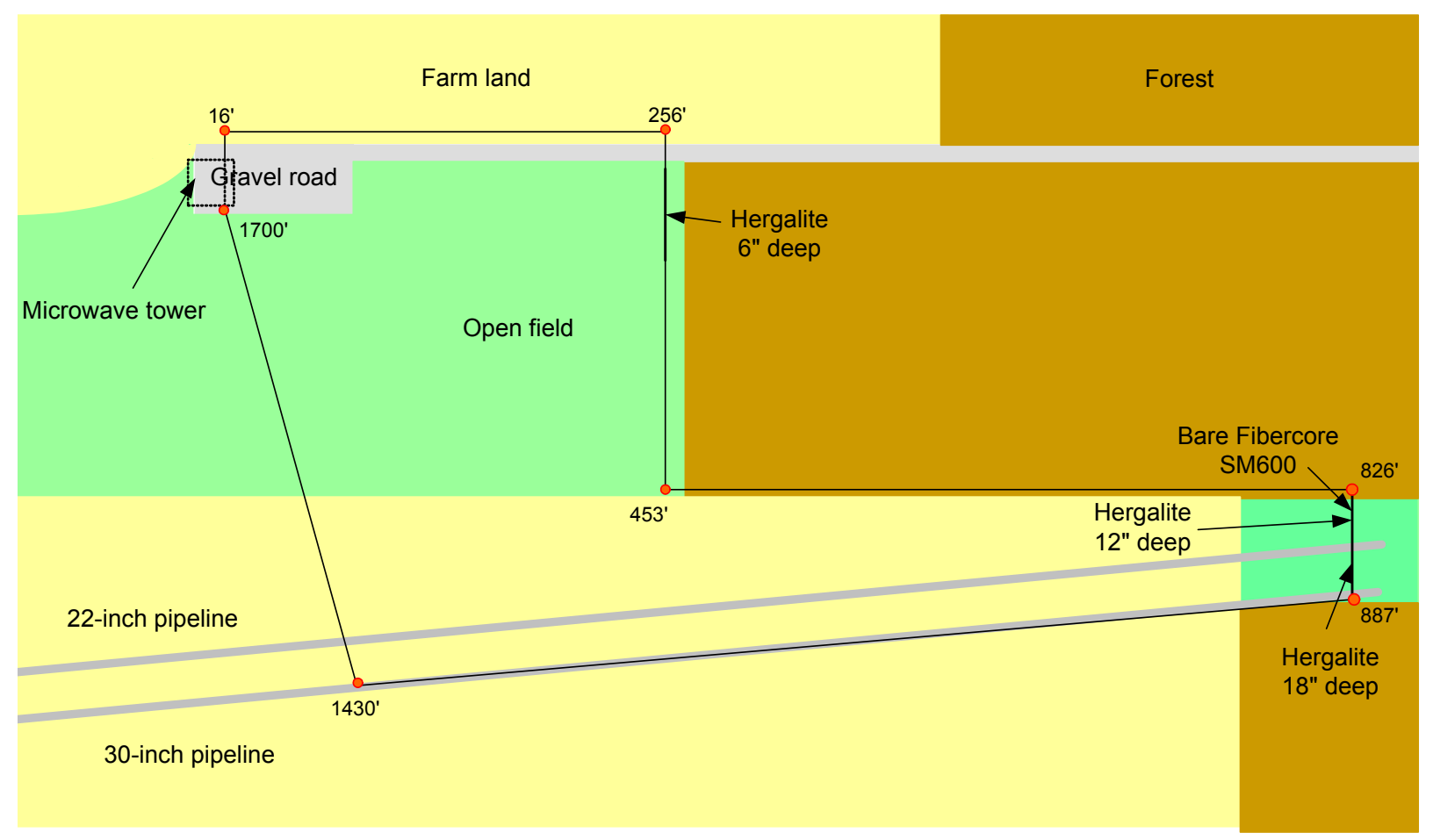

FIGURE 7. SCHEMATIC OF THE TEST SITE

One 50-foot length was buried 6-inches deep. The second 50-foot length was buried at two depths 12 and 18 inches. Unfortunately, the Corning ${ }^{\circledR} 50 / 125$ fiber that was to be a continuous loop broke between the two sections of Hergalite. Access to the far end of the $1 / 2$ loop of Corning ${ }^{\circledR} 50 / 125$ is provided in an electrical box (at 887 feet). The optical fibers were buried at several depths, ranging from 6 to 24 inches. This arrangement will permit sensitivity tests at a range of depths. The deepest depths permit passage of a plow over the optical fiber with out damaging it, thereby minimizing the portion of the field off limits to the farmer.

Emphasis is on establishing sensitivity to encroachment activities; we will address durability issues later. In that approach, we buried a short section of bare Fibercore SM600 fiber. The Hergalite was packaged in a paper sleeve, permitting it to slide. The paper sleeve was sandwiched in duct tape to provide some strength. The soil backfill was completed before the soil froze. The exception was over the sensing areas containing the Hergalite which was completed after a cold snap froze the soil approximately 6-inches deep. The frozen soil was excavated to expose unfrozen dirt. This was broken up and used to cover the sensing fibers. Then the remaining soil was backfilled, but not compacted. We verified continuous light path from the electrical boxes through each sensing fiber, both during and after the fibers were installed. 
Thus we have optical fiber sensors:

- $\quad$ Buried at 4 depths

- Parallel and perpendicular to the gravel road

- Perpendicular to the 22-inch pipeline

- 24 inches above the 30-inch pipeline

- With one length with all 4 fiber types side-by-side.

ANR Pipeline will provide access to a range of construction equipment, including an ATV; rubber-tired trucks, backhoe, and cherry picker; track mounted 36,000 and 40,000 pound excavators and track mounted bulldozers John Deere 450 (15,000 pounds) and John Deere 750 (25,000 pounds). 


\section{SUMMARY OF PROJECT STATUS BY TASK}

\section{Task 1. Research Management Plan}

The draft "Research Management Plan" was written. The DOE Contracting Officer's Technical Representative (COR) made suggestions to improve the plan. GTI made the improvements and submitted the final plan. This plan was accepted.

A kick-off meeting was held at GTI on May 14, 2002.

Hazardous Substance Plan was submitted. No hazardous substances will be used or produced at GTI or the pipeline field site.

Task 1 is complete.

\section{Task 2. Technology Status Assessment.}

GTI prepared and submitted a draft report describing the current state-of-the-art of the encroachment detection and impact detection. The DOE COR made suggestions to improve the report. GTI made the improvements. The final version was approved by the COR.

Recently, DOE requested technical assessment fiber optic system for a right-of-way encroachment detection being introduced into the United States. Based on available information, that approach has an unacceptable drawback for use in densely populated urban sites.

With the exception of updates, Task 2 is complete.

\section{Task 3. Construct and Program Custom OTDR}

Task 3 is to design, construct and program a custom Optical Time Domain Reflectometer (OTDR) capable of collecting and storing a waveform digitized as a function of time from each $\sim 2$ meter section of optical fiber.

The computer hardware is purchased and OTDR software is written. The software will be tested after the remainder of the OTDR is constructed and functioning as desired. The laser diode drive circuitry and the photodiode detector circuitry are designed and built. We are in the process of debugging and refining the circuitry. Several problems have been encountered with the electronics. Most of these were related to electrical components not performing to the manufacturer specifications. Design-arounds were developed. Although, we believe most of the 
problems have been fixed, the OTDR is still not functioning as desired. The debugging process continues.

\section{Task 4. Select, Install, and Test Optical Fiber Cables}

GTI's work with FOIDS and a commercial OTDR demonstrated that construction equipment can be detected with an optical fiber system. However, these measurement techniques do not have the spatial or time resolution required to characterize and discriminate among interferences. Therefore, optical fiber sensitivity and durability will be evaluated.

GTI has identified the most promising optic fibers for use as the distributed sensor. A suitable test site over an operating transmission pipeline has been found. The original goal was to test the fibers in the laboratory and at GTI's pipe farm facility. Because of the delay's in building a properly functioning OTDR, we have not been able to test the fibers. With the scheduled end of the project quickly approaching, we decided to install the fibers at the fiber site. Thanks to an unusually mild winter, we were able to install the fibers in early January 2003.

This task is complete, except for installation of the fibers at GTI and the long term testing of the fiber properties.

\section{Task 5. Collect Data on Selected Right-of-Way Encroachment Types}

GTI will make measurements of the signals created in the optical fibers as each encroachment type moves over the right-of-way. These data will be used for demonstrating sensitivity of technique and signal discrimination in Task 5.

This task will start after the OTDR is complete and the fibers installed at the field site.

\section{Task 6: Develop Techniques to Distinguish Potentially Harmful from Harmless} Encroachment.

GTI will develop techniques to distinguish potentially harmful from benign interference in the right-of-way. Minimizing the number of false positives is the key technical barrier that must be surmounted for a successful technique.

This task will start after the OTDR is complete and the fibers installed at the field site. 


\section{Task 7. Demonstrate Sensitivity and Discrimination Capabilities}

GTI will demonstrate to NETL the ability to detect construction equipment and to distinguish potentially hazardous from benign encroachment.

This task is not schedule to start.

\section{Technical Problems Encountered}

No technical problems that will impact the ability to perform the project or project schedule have been encountered.

\section{Project Management Issues}

There have been issues that have adversely impacted the schedule.

With the loss of the original subcontractor, new arrangements have been made for a test site in the Chicago area. ANR Pipeline will charge for the installing of the fiber. They will donate the equipment operation during the testing phase. This is not a budgetary issue as the original subcontractor was to be paid for these services.

The construction of the OTDR is behind the original schedule. The first delay was in hiring the electrical/electronics engineer to help with the construction of the custom OTDR, data collection, and associated signal processing. This process took longer than anticipated. A highly qualified person with much experience in programming and digital signal processing was hired February 18 and became full-time June 1, 2002. We had expected to catch-up on the schedule and meet the original schedule goals. However, the problems with the electrical components delayed completion of the OTDR. We are six months behind the planned schedule. After the OTDR is functioning properly and the first field measurements are made, we will be able to provide a revised time schedule. With the additional effort to get back on schedule, the spending rate has reached the original rate. More money than planned was spent in getting the OTDR to function properly. ANR Pipeline's donation of the equipment and operators during the field testing (compared to the original plan of paying the subcontractor) compensates for this.

\section{Action Requested of DOE NETL Project Manager}

There are no action items requested of the DOE COR. 


\section{Work Planned for the $1^{\text {st }}$ Quarter of 2002}

The following items are planned for the next quarter:

- Complete fine-tuning of the OTDR

- Test the programming the digital oscilloscope to collect successive waveforms, store the data, and create waveforms corresponding to a specific distance along the fiber

- Test the ability to detect loads/vibrations on optical fiber in the laboratory.

- Begin testing at the test site

\section{CONCLUSION}

Fifteen months into the 24 month project, the following conclusions can be drawn:

- The initial assessment of backscattering mechanisms indicates that any of several choices of optical fiber cables and light sources should be suitable for detecting encroachment.

- The problems in building the custom OTDR, should not affect the technical success of the project. 


\title{
LIST OF ACRONYMS AND ABBREVIATIONS
}

\author{
COR - Contracting Officer's Technical Representative \\ DOE - Department of Energy \\ DSLP - Digital Sonic Leak Pinpointer \\ FERC - Federal Energy Regulatory Commission \\ FOIDS - fiber optic intrusion detection system \\ GPS - global positioning system \\ GRI - Gas Research Institute \\ GTI - Gas Technology Institute \\ IGT - Institute of Gas Technology \\ IRNG - Infrastructure Reliability of Natural Gas \\ LED - light emitting diode \\ NETL - National Energy Technology Laboratory \\ NT - Nicor Technologies \\ OTDR - optical time domain reflectometry
}

\section{REFERENCES}

1. Analysis of DOT Office of Pipeline Safety (OPS) Natural Gas Pipeline Operators Incident Summary Statistics for 01/01/86 -06/21/1999. The statistics are available from OPS's website http://ops.dot.gov/

2. National Transportation Safety Board Pipeline Accident Report for Texas Eastern Transmission Corporation Natural Gas Pipeline Explosion and Fire, Edison, New Jersey, March 23, 1994. PB95-916501. NTSB/PAR-95/01.

3. Francini, R.B., Kechter, G., Leis, B.N., Narendran, V.K., Kurmer, J., "Real-Time Monitoring to Detect Third-Party Damage: Phases III and IV" GRI Final Report GRI01/0160, April 1999.

4. Doctor, R. H., Dunker, N. A., “ Field Evaluation of a Fiber Optic Intrusion Detection System-FOIDS” " GRI Final Report GRI-95/0077, December 1995.

5. From the physics and astronomy website: www.phy-astro.gsu.edu

6. Fiber Optic Sensors an Introduction for Engineers and Scientists, edited by Eric Udd, John Wiley \& Sons, Inc. New York 1991. pp-29-31.

7. John M. Senior, Optical Fiber Communications, Prentice/Hall International 1985, pp 6970 